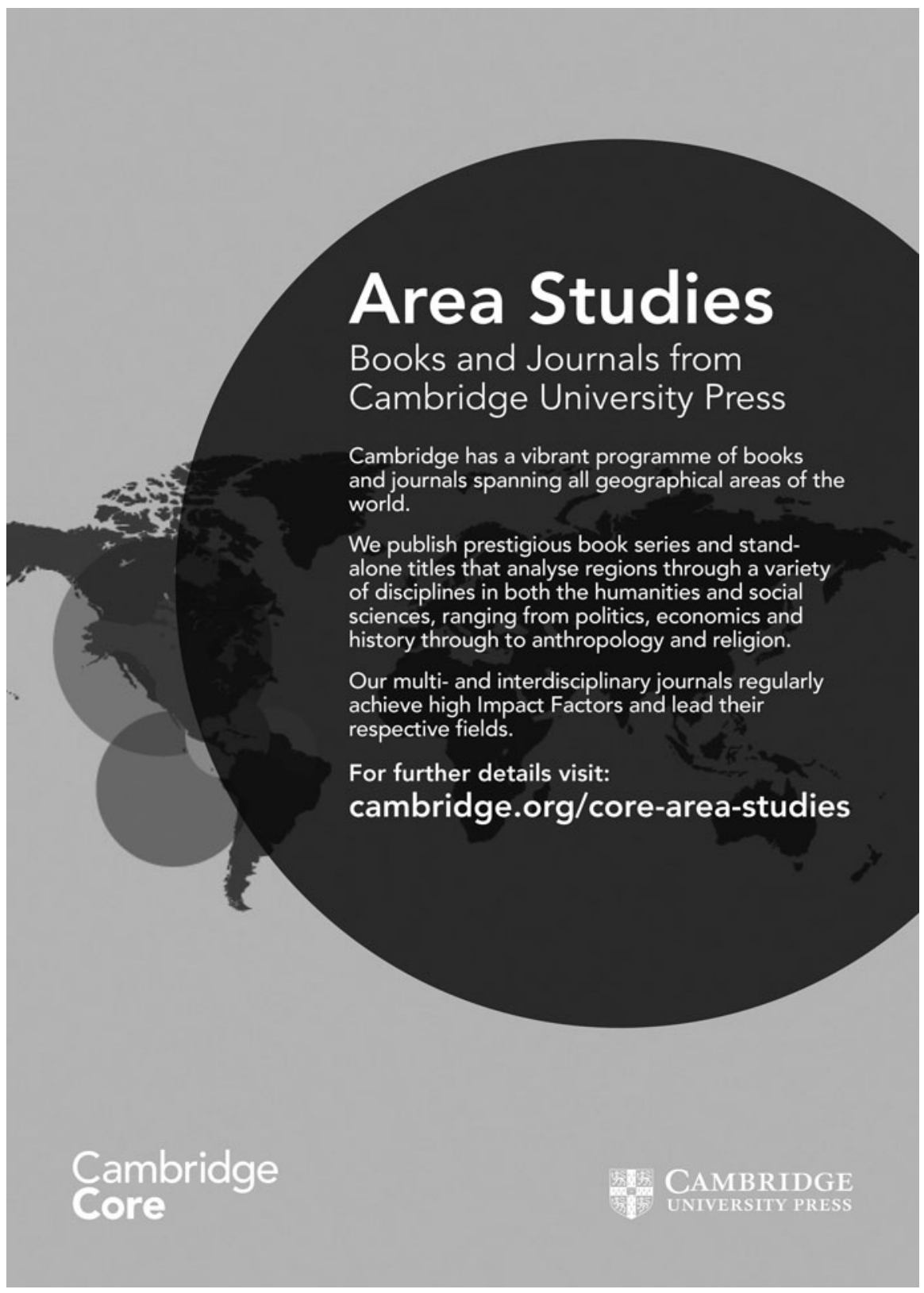




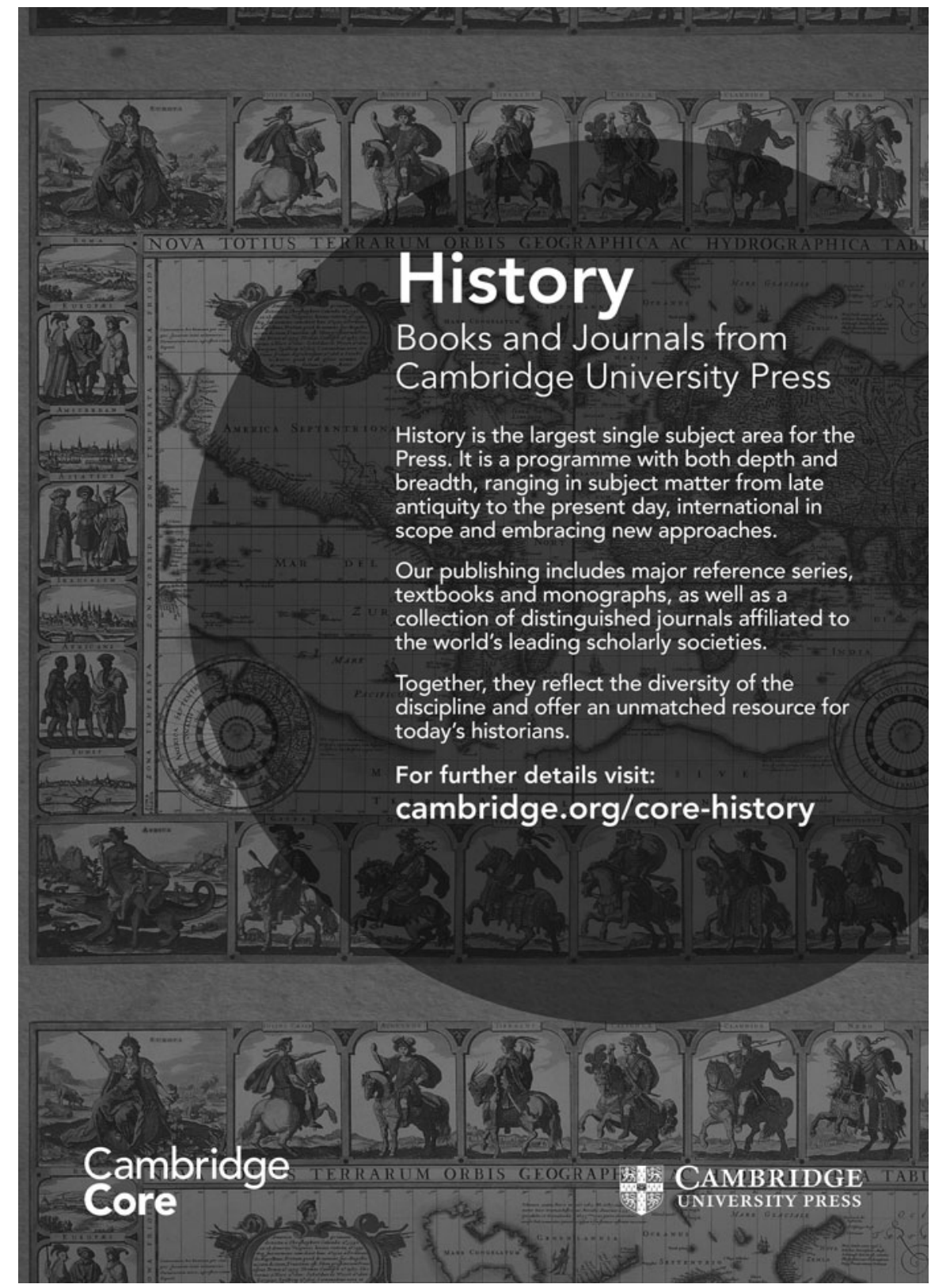




\section{GUIDELINES FOR CONTRIBUTORS}

The Bulletin of the School of Oriental and African Studies $(B S O A S)$ is an international journal publishing research and reviews in the arts and humanities, including history, languages and linguistics, literatures and philosophies, religions, material culture and music, relating to Africa and Asia. It has been a platform for new ideas and discoveries since 1917. It publishes material by scholars from all over the world and its Editorial Board is advised by specialists from many countries. Authors are encouraged to situate their articles within the broader context of the field of studies and to write in such a way that they be understood by interested non-specialists. $B S O A S$ welcomes submissions on the history, religions, languages, laws, artistic cultures, and related fields pertaining to the societies and countries of Asia and Africa.

\section{Article submission}

Articles for consideration should be uploaded to the journal's ScholarOne Manuscripts site at: https://mc.manuscriptcentral.com/bsoas. Please ensure your article is anonymous by removing all information which might lead to your being identified. In case of difficulty using the site please email: bulletin@soas.ac.uk for assistance. More detailed contributor guidelines can be found on the ScholarOne site. The maximum length for a paper is 12,000 words including all notes, references and appendices. The Bulletin publishes abstracts (around 150 words) and keywords for all articles.

Submission of an article implies that it has not been previously published or accepted for publication elsewhere, neither should articles be simultaneously under consideration for other journals.

Spelling is British English. On acceptance of articles authors are required to supply an MS Word version of their paper using Unicode-compitable fonts.

References. The preferred style of reference is citation by author and date, e.g. Robinson (2000: 80) including a complete reference list giving full bibliographical details as follows:

Robinson, Chase F. 2000. Empire and Élites after the

Muslim Conquest: The Transformation of Northern

Mesopotamia. (Cambridge Studies in Islamic

Civilization.) Cambridge: Cambridge University Press. A clear system of abbreviations or other critical apparatus should be used for archival and manuscript sources.

The following system of references will also be accepted: a first footnote citation giving full bibliographical data,

e.g. M. Boyce, Zoroastrianism: Its Antiquity and Constant
Vigour (Columbia Lectures on Iranian Studies, 7, Costa Mesa: Mazda, 1992), 187. Thereafter by short title; op. cit. and ibid. should be avoided and author surname and a short title used instead.

Titles of books and journals are italicized with initial capitals. Citation by volume and part is in the following form: BSOAS 60/1, 1997, 231-9. Titles of articles are roman within double quotation marks.

Illustrations and scripts. Line drawings, graphs, etc., should be supplied electronically. Authors are responsible for clearing copyright permissions and providing the acknowledgement line. Full details on preparing illustrations for publication can be found in the Cambridge Journals artwork guide online: journals.cambridge.org/artworkguide. Photos and non-roman scripts, including Chinese and Japanese characters, will only be accepted where they are essential to the text. Scripts and characters should be provided electronically, in a Unicode-compatible font for electronic typesetting; in case of difficulty please contact the editorial office in the first instance.

Transliteration. Diacritical marks must be given in full and consistently on all transliterated text (though note that where words have become Anglicized this does not apply) More detailed guidelines on the romanization of various language groups are available from the editorial office. Further guidelines on the production of articles are sent out on acceptance for publication.

\section{Proofs}

First proofs of articles and reviews are sent to authors and should be returned by the deadline given. Corrections should be limited to factual and typographical errors. Proofs are sent in the form of a .pdf attachment to an email message.

\section{Copyright}

It is a condition of publication that authors assign copyright to SOAS, University of London. This ensures that requests from third parties to reproduce articles are handled efficiently and consistently and will also allow the article to be as widely disseminated as possible. In assigning copyright authors may use their own material in other publications provided that the journal is acknowledged as the original place of publication. Authors wishing to publish under the 'gold' open access model under a CC-BY licence are welcome to do so, and can pay the APC on acceptance of their article for publication. 


\section{Contents}

\section{Articles}

419 The Arabic of the Islamic conquests: notes on phonology and morphology based on the Greek transcriptions from the first Islamic century AHMAD AL-JALLAD

441 Why was the Dome of the Rock built? A new perspective on a long-discussed question MILKA LEVY-RUBIN

465 Une requête (petition) au calife fatimide al-Hākim bi-amr Allāh (Rémondon 1, musée du Louvre)

ANNE REGOURD

473 Identification of a small fragment of Mani's Living Gospel (Turfan Collection, Berlin, M5439) MOHAMMAD SHOKRI-FOUMESHI

485 Two Iranian loanwords in Syriac NICHOLAS SIMS-WILLIAMS

491 Old Khotanese type A stems in -a- and -eDOUG HITCH

On "personal protective deities" ('go ba'i lha) and the Old Tibetan verb 'go BRANDON DOTSON

547 Entrepreneurship in the textbook business in modern East Asia: Kinkōdō of Meiji Japan and the Commercial Press of early twentieth-century China

BILLY K.L. SO AND SUFUMI SO

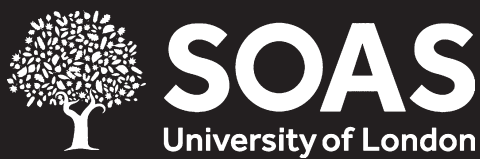

Published by Cambridge University Press on behalf of SOAS, University of London 